\title{
Becoming more systematic about flexible learning: beyond time and distance
}

\author{
Wim de Boer and Betty Collis* \\ University of Twente, The Netherlands
}

\begin{abstract}
Changes in higher education frequently involve the need for more flexibility in course design and delivery. Flexibility is a concept that can be operationalized in many ways. One approach to conceptualizing flexibility within courses is to distinguish planning-type flexibility, which the instructor can designate before the course begins and which needs to be managed when the course is offered, for interpersonal flexibility, which relates more to the dynamics of the course as it is experienced by the learners. Course management systems (CMSs) offer options that can support both of these sorts of flexibility, if instructors use the CMSs with a systematic frame of reference. The instructor faces challenges in managing both types of flexibility, but the experience at one institution shows that being systematic about flexibility choices and ways to support those choices in the institutional CMS can help in meeting these challenges.
\end{abstract}

\section{Introduction: flexibility in higher education}

Traditional universities are in the process of providing quality education for rapidly diversifying student cohorts (Observatory of Borderless Education, 2002; Middlehurst, 2003). This change process is multi-faceted including a broader range of students, changing roles of instructors, more-flexible curricula, new delivery methods, new contacts between universities and other partners, and the globalization of higher education (Guri-Rosenblit, 1998). Bates (2001) argues that increasingly flexible learning is necessary in this changing situation. This is not a new orientation: Van den Brande, in the foreword of a comprehensive book on open and flexible learning, indicated that 'there must be more flexibility to meet the needs of the learner, through adaptability to different learner needs, learning patterns and settings, and media combinations' (1993, p. xxi). Flexibility can occur within the individual course, as a

\footnotetext{
*Corresponding author. Faculty of Behavioural Sciences, University of Twente. P.O. box 217, 7500 AE Enschede, The Netherlands. Email: B.A.Collis@utwente.nl
} 
result of choices made by the instructor. Flexibility can involve options in course resources, in types of learning activities, in media to support learning, in options for communication and social interaction, and many other possibilities (Ling et al., 2001; Zimitat, 2002).

However, despite this attention, finding a systematic way to increase the flexibility of learning in higher education rarely moved much beyond provision of time flexibility and place flexibility (Ling et al., 2001). Web-based resources such as coursemanagement systems (CMSs) are frequently used, but primarily to allow flexible access to information rather than for the systematic provision of options to learners in terms of a range of learning activities, resources, and supports (Mioduser \& Nachmias, 2001; Oliver \& Herrington, 2001). Instructors need help in making decisions about how to design a CMS environment to increase the flexibility of their courses beyond flexible information access (Morgan, 2003).

In order to increase instructors' support of flexibility within their courses in higher education, at least two key steps need to occur: instructors need to think systematically about different aspects of flexibility when designing their courses, and instructors need to design and manage their CMS environments in order to support the options for flexibility that they will make available in their courses. By reviewing and synthesizing several pieces of research, this paper addresses these two steps and illustrates the general ideas with examples from a particular institution.

\section{Thinking systematically about flexibility}

In this section, we discuss a line of research in which we have been involved since the mid-1990s, with the focus on identifying sets of options with respect to flexibility that can help instructors make choices about what can be offered in their courses. Based on a literature review, 12 forms of within-course flexibility were identified that were subsequently used as the basis for an international survey. From a factor analysis of the survey responses, two main dimensions for within-course flexibility were identified that help instructors in the systematic consideration of options for their own courses. Each of these is summarized here.

From a literature review and confirmatory interviews during 1995-1997, Collis et al. (1997) identified 19 dimensions of course flexibility, which were grouped in five sets: flexibility related to time, to content, to entry requirements, to instructional approach and resources, and to delivery and related logistics. Twelve of these represent aspects of flexibility that can be determined by instructors within their decisions for course design and management. Table 1 presents these 12 aspects of flexibility under instructor control.

\section{Methodology}

To examine the extent to which these forms of flexibility are being offered in practice by instructors in higher education and also to see whether the set can be simplified further in terms of main dimensions useful to instructors in their design and 
Table 1. Instructor choices in flexibility, grouped according to main categories

Flexibility related to time

Flexibility related to content

Flexibility related to instructional approach and resources

Flexibility related to course logistics
Times for starting and finishing a course, Times for submitting assignments and interacting within the course, Flexibility in pace of learning

Topics of the course, Orientation of course events (theoretical, practical), Assessment standards and completion requirements

Ways in which the course is experienced (face-to-face; group, individual, combinations), Language to be used during the course, Types and sources of learning resources, Assignments required for the course

In location of specific learning events, In times of specific learning events

course-management activities, questions relating to them were asked as part of an international comparative study on changes in higher education (2000-2002) (Collis \& Van de Wende, 2002). In this international study (nine countries, including seven in Europe), over 650 respondents (instructors, decision-makers and support professionals) within higher-education institutions gave their opinions relating to the variables in a model for predicting change. The purpose of this project was to study factors that influence current models relating to change and technology use in higher education, and that predict how institutions are likely to evolve, given their current conditions. The study was primarily sponsored by the SURF Foundation in The Netherlands and by the Bertelsmann Foundation in Germany.

A questionnaire was developed and piloted. A set of items related to the flexibility dimensions in Table 1 were part of the questionnaire. For each of the 12 dimensions, instructors were asked 'To what extent do you offer options relating to each of the following to students in your own courses?'. The response options were: (1) No flexibility, (2) (Unlabelled), (3) Some flexibility, (4) (Unlabelled), (5) Extensive flexibility.

\section{Findings}

A selected sample of universities in the nine target countries was identified, using information sources in national Ministries of Education. Information and Communication Technologies contact persons were contacted at each of the institutions, and asked to approach decision-makers, instructors, and support personnel in their institution with the request to respond to the questionnaire. Approximately $30 \%$ of the approached institutions responded fully to the survey (for full details, see Collis \& Van der Wende, 2002). From these institutions, 347 instructors responded to questions relating to their current teaching practice and their predictions about this practice several years in the future. Table 2 presents the means and standard deviations 
Table 2. Amount of flexibility within courses currently offered by instructors within their own courses in higher education $(n=347)$

Mean Standard

deviation

Flexibility related to time

Times for starting and finishing a course

$1.82 \quad 1.02$

Times for submitting assignments and interacting within the course

Flexibility in pace of learning

Flexibility related to content

Topics of the course

Orientation of the course (theoretical, practical)

Assessment standards and completion requirements

Flexibility related to instructional approach and resources

Ways in which the course is experienced

Language to be used during the course

Types and sources of learning resources

Assignments required for the course

Flexibility related to course logistics

Flexibility in location of learning

Note: $1=$ no flexibility, $5=$ extensive flexibility.

of the responses of the instructor sample to the items relating to the flexibility dimensions presented in Table 1 .

Table 2 shows that most of the responses were within a standard deviation of 'Some flexibility'. The relatively low scores confirm the observation that instructors are not yet regularly offering options with respect to flexibility in their courses, although variation in terms of types of flexibility does occur.

In order to further examine patterns in the data, a principle components analysis was carried out on the responses to the nine items, using Varimax rotation with Kaiser normalization, converging after nine iterations (De Boer, 2004). Two factors with eigenvalues greater than 1.00 were retained for interpretation. These two factors explain $45.95 \%$ of the variance. Table 3 presents the loadings of the flexibility-dimension variables on the two retained factors. The loadings in bold indicate the factor related to each variable for subsequent interpretation. For convenience, loadings less than 0.200 and dimensions with loadings less than 0.200 on the factors retained for interpretation are not presented.

Factor 1 relates strongly to six variables all involved with the decisions the instructor makes in setting up a course. These could be called 'planning flexibility'. Factor 2 relates most closely to the learning setting as experienced within the course, the 
Table 3. Rotated factor solution, flexibility dimensions as practiced by instructors $(n=347)$ within their courses

\begin{tabular}{lcc}
\hline & \multicolumn{2}{l}{$\begin{array}{l}\text { Factors, eigenvalues, and percentage of } \\
\text { variance accounted for }\end{array}$} \\
\cline { 2 - 3 } $\begin{array}{l}\text { Flexibility dimensions } \\
\text { Factor 1, eigenvalue } \\
=3.085,34.28 \%\end{array}$ & $\begin{array}{c}\text { Factor 2, eigenvalue } \\
=1.051,11.67 \%\end{array}$ \\
\hline Times for starting and finishing a course & 0.326 & 0.263 \\
$\begin{array}{l}\text { Times for submitting assignments and interacting } \\
\text { within the course }\end{array}$ & 0.601 & \\
Topics of the course & 0.686 & 0.204 \\
$\begin{array}{l}\text { Orientation of the course (theoretical, practical) } \\
\text { Assessment standards and completion requirements }\end{array}$ & 0.775 & 0.252 \\
Assignments required for the course & 0.695 & 0.544 \\
Modality and origin of learning resources & 0.633 & 0.578 \\
(instructor, learners, library, WWW) & 0.350 & 0.816 \\
Ways in which the course is experienced & 0.275 & \\
Language to be used during the course & & \\
\hline
\end{tabular}

flexibility that students would benefit most from interpersonally as the course proceeds. Although the results of the factor analysis do not present a clear division between planning/logistic and pedagogic decisions, they do indicate that a systematic approach to within-course flexibility could proceed using these two dimensions.

\section{Applying the flexibility dimensions to the design and use of CMSs}

CMSs, sometimes called Virtual Learning Environments, are Web-based databasedriven systems that enable or support learning (for an overview, see http:// www.edutools.info/course/index.jsp, in which more than 70 commercially available CMSs can be compared around 40 different features). Despite this variety, the main components of a typical CMS can be arranged around three sorts of tools for learning support:

- Tools for course organization.

- Tools for communication.

- Tools for content and assignment creation and delivery.

The two dimensions relating to planning and interpersonal flexibility can be set out against these characteristic elements of a CMS, in order to suggest how each type of flexibility can be enabled or supported through a CMS. Table 4 presents such an overview, where the flexibility examples are adapted from Collis (1998). The functionalities related to the three general sets of tools are common to most if not all CMSs. The instructional and management decisions come from the instructor, not the CMS. 
Table 4. Flexibility dimensions set out against general CMS characteristics (adapted from Collis, 1998)

Instructional or management decisions that can be made by the instructor, in terms of the flexibility dimensions

$\begin{array}{lll}\begin{array}{l}\text { Course } \\ \text { organization }\end{array} & \text { Course updates } & \begin{array}{l}\text { Updates placed and read } \\ \text { anywhere and anytime }\end{array} \\ & \text { Course information } & \begin{array}{l}\text { Accessible anywhere and } \\ \text { anytime }\end{array}\end{array}$

Course planning

Fewer face-to-face sessions

Students may be at different locations during one course/ session

Activities

Communication Lecture sessions

Plan (portions of) the activities to be placeand time independent

Plan fewer face-to-face meetings

Capture sessions as digital audio and/or video and link to the course WWW site for later study

Let students who were not at the session review notes and ask questions via the CMS

Communication

Add a communication center to the course WWW site so that groups of students, or individuals, can be easily contacted via e-mail

Interpersonal

Offer a variety in background information about the course, offer different sorts of introductory activities

Expand sessions by having activities before and after

Learners' own experiences can be used as input for activities

Materials submitted from the activities can be used as new learning materials

Different activities to choose from for different learner characteristics

Use chat facilities/real-time communication tools via the Internet for students in different locations to do follow-up activities

Investigate new forms of contact sessions, offering learners a choice

Stimulate students to interact with each other via different activities involving collaboration. peer review and discussion 
Table 4. Continued

Instructional or management decisions that can be made by the instructor, in terms of the flexibility dimensions

\begin{tabular}{|c|c|c|}
\hline CMS component & Tool functionalities & Planning \\
\hline & Group work & $\begin{array}{l}\text { Plan that group members } \\
\text { work collaboratively on } \\
\text { projects without needing to } \\
\text { be physically together, use } \\
\text { shared workspace tools } \\
\text { along with other } \\
\text { communication and } \\
\text { reporting tools }\end{array}$ \\
\hline
\end{tabular}

Interpersonal

Have opportunities for students to use relevant contexts and authentic problems

Discussions

Feedback

Content and assignment creation and delivery
Make use of a discussion board for reflective discussions about course topics as a major activity in the course if the students see each other regularly or not

Choose from different forms of feedback: i.e., peer feedback, automatic feedback; model answers

Provide optional resources
Have options for those students that have to or want to work alone

Let students moderate and sum up online discussions

Plan to involve experts from outside the course in discussions

Have peer-support and peer-feedback opportunities; Use a portfolio approach for feedback

Guide students to use the Web as a resource for all sorts of resources (i.e. multimedia/reports/ examples) and let students contribute materials that they fine or create during the course

Assignments
Make instructions, marking scheme, model answers, and feedback available via the CMS
Facilitate students using each others' submissions as learning resources once these are available as part of the CMS environment 
Table 4 confirms that, if designed appropriately a CMS can be a tool to support instructors to be more flexible in their teaching. The two types of flexibility can be clearly supported in the options that a typical CMS offers. In addition, a number of procedures have been suggested in Table 4 to operationalize flexibility in practice, in terms of the two dimensions of flexibility from the empirical study. CMSs therefore can be used as integrated tools for individual instructors to support increased flexibility in their courses.

The rows in Table 4 are organized around familiar common components of a CMS. The nine items retained from the factor analysis as loading highly on the two flexibility clusters can be mapped onto the instructional and managerial ideas listed in the two right-side columns. The planning dimensions can be seen to underlie the specific examples in the 'planning' column, and the 'interpersonal' dimensions can underlie the similarly named column. Often a particular flexibility dimension, such as that related to planning for the assignments within the course, can be seen in a number of the decisions in the associated column. The next section gives detailed examples of how this sort of systematic analysis is being used in practice.

\section{Case studies: examples from practice}

\section{Methodology}

In the previous section the use of a CMS to support the two major types of flexibility was discussed generically. We have also been studying these general ideas in detailed form and in practical application in our own institution between 1997 and 2003. This section will give specific examples of the flexibility options offered to students at the University of Twente in The Netherlands using the CMS in place at that institution (De Boer, 2004). The cases have been selected to illustrate the principles identified in the previous sections. The comments given relate to our inventories of what the instructors in this specific institution are doing with respect to offering flexibility and supporting this via a CMS. It is important to take into account that the CMS only supports the flexibility that instructors choose in their instructional design or managerial decisions. The first six examples correspond to the six variables loading on the Planning flexibility dimension as presented in Table 3 and related to a CMS in Table 4, while the last three examples correspond to the three variables loading on the Interpersonal flexibility dimension in Table 3, which are related generically to a CMS in Table 4. Most of the examples shown could be carried out with any CMS.

\section{Case studies: Planning flexibility}

\section{Times for starting and finishing a course}

Flexibility in the times that students can start and end a course is being offered by instructors through the use of the CMS. Some offer flexibility on both sides of the 
defined times for a course. Instructors set up their course environment before the first session starts. The most elementary information and organization should be made clear through the CMS. This gives an option for students to start their own planning activities before the course actually starts. As a minimum within most courses, the most elementary course information, content, and activity descriptions in the CMS course environments are up and running two weeks before the first session, or other kick-off activity. In addition to this, a number of instructors use the CMS for extending course dates. One example is when a small number of students are attending a course (e.g. a specialized elective in the Masters programme), and the students enrol at different times during the year. Figure 1 shows the 'Roster' of a course environment of the educational programme for students in a certain teacher-training programme that offers this kind of flexibility. Different rows of the 'Roster' can be set up for different groups of students. (The Roster in the TeleTOP CMS is a matrix-like template that allows the instructor to set up the course organization in whatever table-based design the instructor chooses. Pages can be linked to each cell of the Roster to offer instructions, content objects, and assignment resources, and via which the learners can submit their assignments and receive feedback.)

\section{Times for submitting assignments and interacting within the course}

The number of activities per course with graded submissions has increased since the introduction of the CMS, and the number of scheduled contact sessions has decreased. When using the CMS, instructors are offering opportunities to create flexibility for students in terms of submission dates, while not themselves losing the overview on these activities. The instructors use an 'administration tool' to see the submissions of students sorted in various ways, if feedback has been provided, and if a grade has been given. All instructors make use of the administrative overviews in the CMS, and many note that these are highly valuable if not indispensable when they offer more and more variations to learners in terms of assignment due dates. Many instructors are concerned about offering options to students in terms of the timing of submissions while still maintaining control over their own time. One way of doing this is to indicate to students that if they submit by the specified due date, they can expect personalized feedback from the instructor within a set time (such as one week).

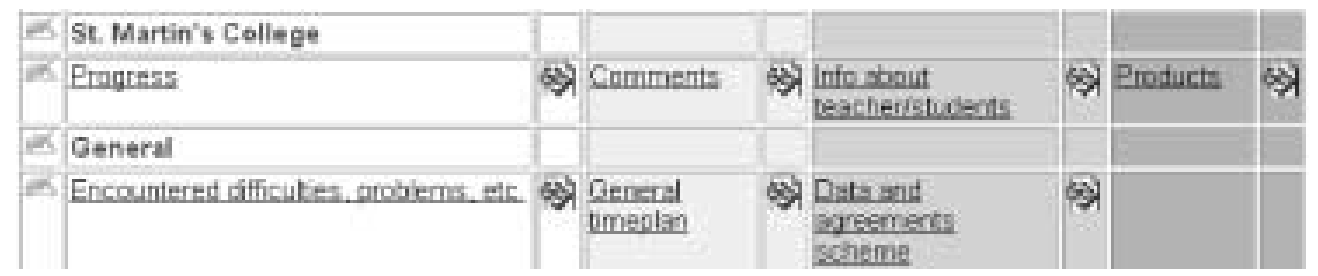

Figure 1. Example of a Roster with activities that are not related to a specific time. Some are only visible for a subset of students (in this case, 'St Martin's College') while others are seen by all students 
However, if students wish more flexibility and want to submit work later, they may do so-but the instructor cannot promise to have time allocated to given personalized feedback, only a score and a reference to a model answer.

\section{Topics of the course}

There are many possibilities for offering options that relate to the topics of a course. A number of instructors have adopted the 'contributing-student' pedagogy (Collis \& Moonen, 2001), in which learners contribute in different ways to the resources available in the CMS and then build on those contributions as the basis of subsequent activities. Figure 2 shows some of the sorts of contributions that are becoming common within the university.

With these options the content can be related to the context of the learners, which is a strong and flexible way to offer students relevant learning experiences. Examples of options for course materials involving student contributions that are being used by our instructors include:

- Searching for additional information or examples and making these available for others.

- Working with a case as a basis for problem-solving and contributing some additional materials for the case for use by others.

- Participating in a role-play situation and leaving some record of the results of the role play for others to consider.

- Creating a report to then be used as a learning resource by others.

\section{Roster, After the session}

\section{Assignment 1: Part 1: Due 4 April, Part 2: Due 6 April, 10 pts}

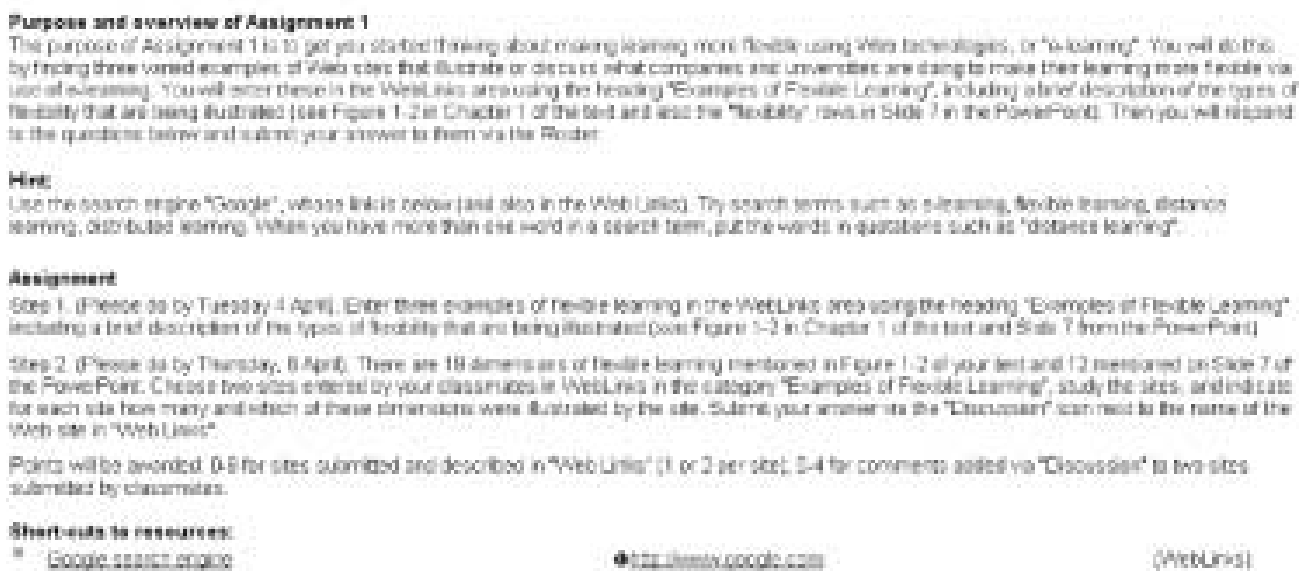

Figure 2. Building on contributions: submissions made by participants (or re-used from previous participants) can be built upon in subsequent activities 
- Creating a product, such as a multimedia resource or a design, that is also a resource for others.

- Extending and applying theoretical principles in new settings and adding these results to a course repository of extension materials.

- Testing one's insight through the development of test questions to be used by others.

- Participating in a discussion and leaving a record of key aspects of the discussion for use by others.

Different CMS environment functionalities are used for these different kinds of contributions, including shared workspaces, the Roster, and various course repositories.

\section{Orientation of the course (theoretical, practical)}

The way the content of the course is organized so that students can advance with an orientation best fitting their own experiences and contexts is also relevant for the way learning is being made more flexible by a number of our instructors. Figure 3 shows how, within a course, students could choose from two major assignments as the final assignment. One assignment had a more practical focus, and the other a more theoretical focus.

\section{Assessment standards and completion requirements}

When the group of students is not homogeneous, the way instructors deal with the assessment standards and completion requirements is also flexible. One way instructors do this is by organizing subgroups within the course and then making Roster rows that are only visible to specific subgroups. In these different rows, variations on the assessment and completion requirements can be offered to different groups (see Figure 4).

\section{Assignments required for the course}

Among the examples of offering flexibility in assignments is that instructors permit students that already are in a working environment to adopt the assignments in such a way so that they are relevant to their working contexts. Another way in which flexibility can occur is through allowing students to do group work individually, with a

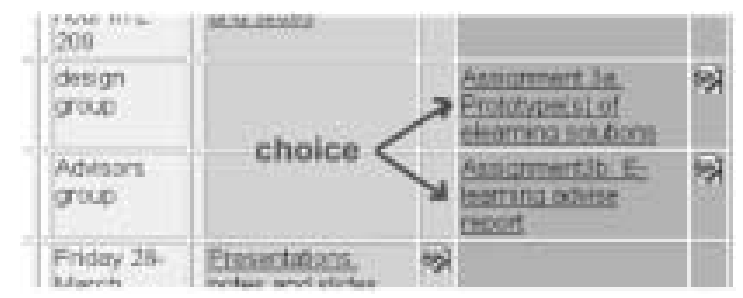

Figure 3. Options in orientation through activities 


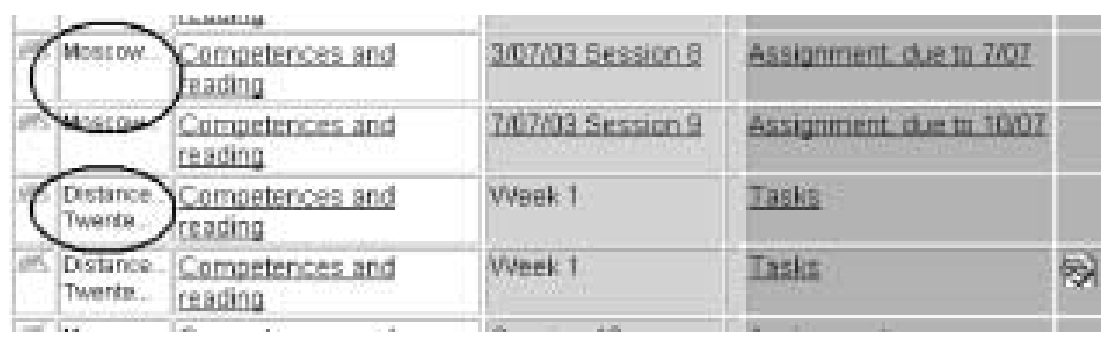

Figure 4. Roster in which two groups (Moscow and Distance students Twente) were distinguished

modified assignment, if this is more convenient to them As another example, when instructors have a number of activities within a course, they sometimes let students choose those activities that would be most relevant or interesting to them individually. Figure 5 shows a course where this kind of flexibility was offered through the tasks.

\section{Case studies: interpersonal flexibility}

Ways in which the course is experienced (group/individual; sessions)

The way a student is participating within a course with regards to working alone or with groups relates to interpersonal flexibility as well as planning flexibility. As operationalized in our institution, this aspect of flexibility is based on fewer lectures and more activities, and flexibility in course planning and communications. It is also

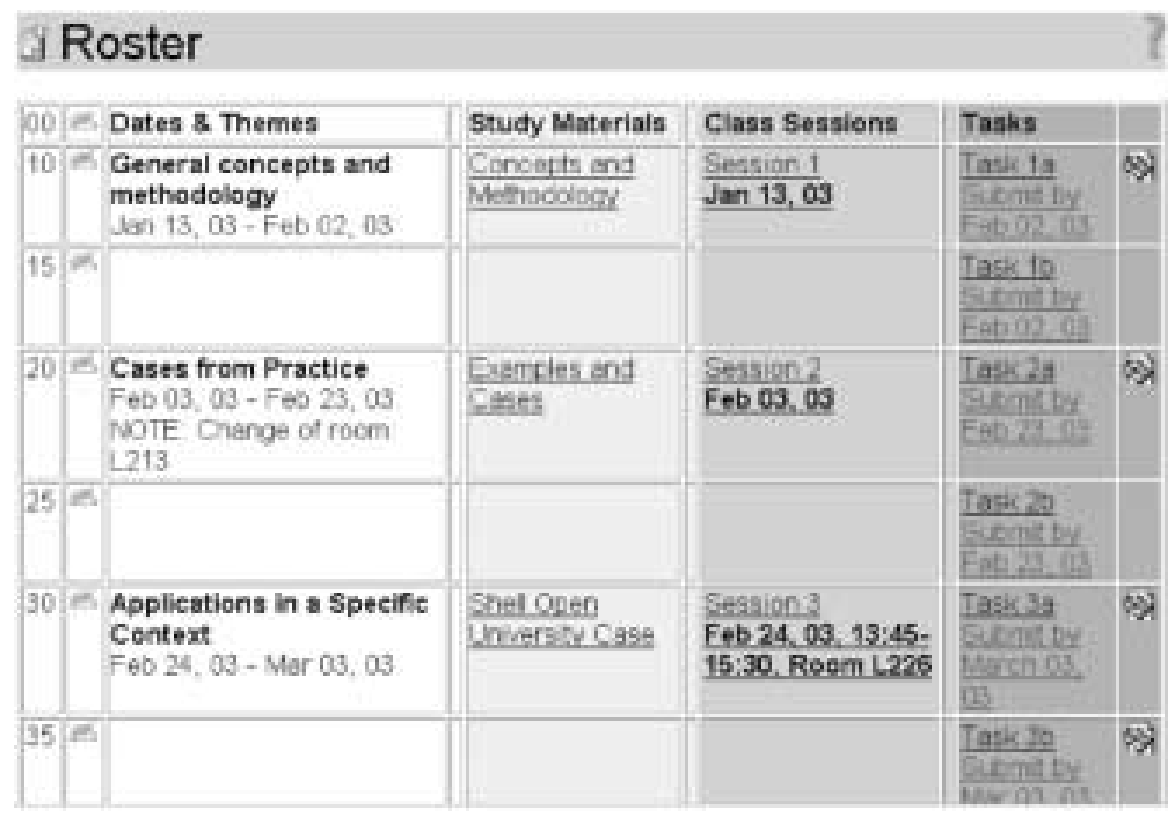

Figure 5. Options in tasks for students: Choose the ' $a$ ' or ' $b$ ' variant 


\begin{abstract}
Overview of class session
8:30-9:00 introduction to each other, to the TeleTOP ste, filing n "Participarts" entries and doing the the put questians belaw

4:00-8:30 Waldhrough al aspects of the course, particutaty the assigments and use af the woricpace

9.30-9.45 Pause

9.45-10.25 Dmensions and models of exarning: Presentation try the instructors (see Powerfort below) Duestions from students wil be irto into the course ste in Duestons and Arswers.

For students who could not be present...

1. Please fil in an entry for yourself in the 'Participarts' area and upinad a digtal phatu if you can Alsu to the tro pol questions below.

2. Stuady the PowerPaink presertation. Chocse ane slide frum the presentation that yuu would Roe to hear mare about and submit a question about this via the Roster.

3. Note Slide $\$ 3$ is a ittie hard to rterpret. The way to read it is to lock at the numberis] in each cclumn and mach thase to the chuices in the frst column. $f$ there is anly one number, there was only cre chace made

Assignment: (indindual assignnent, affer submssion visible for everyone, sutme an Jamuay 30, 2001) Submit a question relating to one of the sheets in the PowerPort. Certain of these questions wil go into the OQA area of the course site.
\end{abstract}

\title{
Submit
}

Figure 6. Example of flexibility in pedagogic approach related to attending a session

based on offering different pedagogical approaches depending on the student's choice. Different CMS functionalities can be used to organize the processes of different (groups of) students. Figure 6 shows an example where this opportunity has been used.

\section{Language to be used during the course}

Within courses that deal with different groups of students, the languages in which students can study and interact within the course could also relate to a flexibility dimension. In an international context the language of all Masters-level courses our university is now English. Sometimes, however, Dutch students prefer to do their assignments in the Dutch language, which they officially have the right to do. Instructors have to deal with this. Also groups of students from outside The Netherlands sometimes wish to work together, in their own mother tongue. Ways to evaluate and learn from each others' experiences and work are important, even where portions of the work may be carried out in a different language. Instructors are identifying different ways in which to blend English communication across groups with the language of choice within groups.

\section{Types and sources of learning resources}

Within the planning dimension there are many options that relate to the resources that students contribute and use for activities. The idea of re-use of students' work 


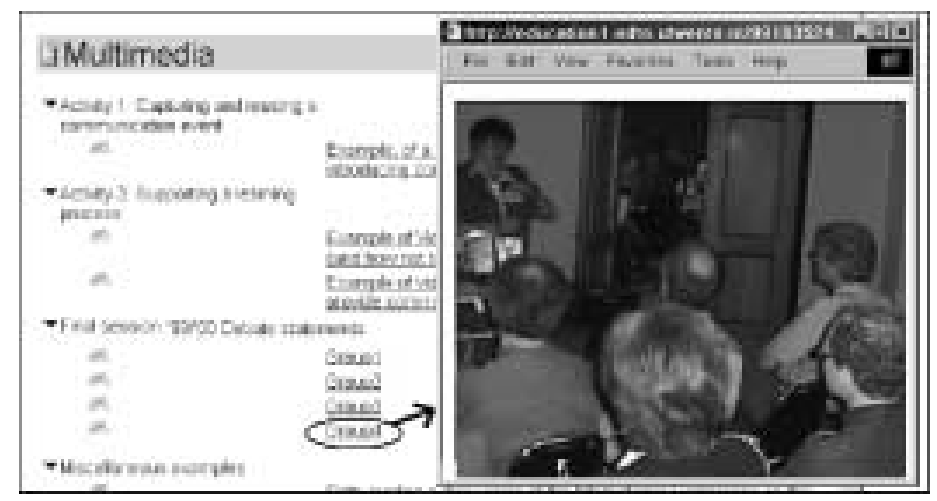

Figure 7. Example of how video captured on the fly is used as a new flexible resource

and of moments of good communication in a course supports flexibility: for those who were not present when a moment of good communication occurred, for example, or to facilitate the development of a substantial database of learning resources that can be re-used and combined in many different combinations (Collis \& Moonen, 2001). An example of how video captures are being used as a flexible resource in a course that had both distance students and on-campus students is shown in Figure 7. Group presentations are captured as streaming video and uploaded in the CMS for follow-up reflections and activities.

\section{Conclusions: what about the instructor?}

A systematic approach to help instructors identify flexibility options and use a CMS to help them offer and manage the options is thus feasible in practice. However, the implications of offering more flexibility for the instructor need to be also analysed and managed.

The planning type of flexibility can occur while maintaining more or less the same teaching and learning programme within a course, but offering more flexibility in terms of logistics. A major concern here is to help the instructor manage the different options that are chosen by the students. However, course pedagogy tends not to be much altered.

However, when interpersonal flexibility is adapted, this often implies a change in pedagogy, such as with more student-centred contributions that relate to the experiences of the individual students and can be re-used by others as learning resources. It is probably harder to make this change to interpersonal flexibility, because instructors need to rethink their courses in terms of the activities within the course and also the assessment of those new activities.

Support for instructors is therefore very important. Research at the University of Twente and beyond shows that support for the instructor can be, and needs to be, improved. In addition, once a clear goal from the management with regard to 
flexibility is communicated, the means to support instructors should not only be focused on the starting period of an innovation. Support needs to be near at hand to help instructors with more complicated instructional problems over time. On one hand instructors should work within an institutional environment that is encouraging them to try new ideas in responding to the needs of their students, and on the other hand the institutional environment should be able to respond quickly to the needs and questions of instructors. Flexibility must be scalable and manageable as well as student-centred and responsive. Helping the instructor to find this balance and manage it via the course CMS remains an issue in practice.

\section{References}

Bates, T. (2001) National strategies for e-learning in post-secondary education and training (Paris, UNESCO/IIEP),

Collis, B. (1998) New wine and old bottles? Tele-learning, telematics, and the University of Twente, in: F. Verdejo, \& G. Davies (Eds) The virtual campus: trends for higher education and training (London, Chapman \& Hall), 3-17.

Collis, B. \& Moonen, J. (2001) Flexible learning in a digital world: experiences and expectations (London, Kogan Page).

Collis, B. \& Van der Wende, M. (2002) Models of technology and change in higher education: an international comparative survey on the current and future use of ICT in higher education (Enschede, CHEPS). Also available online at: http://www.utwente.nl/cheps/documenten/ ictrapport.pdf (accessed May 2003).

Collis, B., Vingerhoets, J. \& Moonen, J. (1997) Flexibility as a key construct in European training: the TeleScopia Project, British fournal of Educational Technology, 28(3), 199-218.

De Boer, W. F. (2004) Flexibility support for a changing university. Doctoral dissertation, Faculty of Educational Science and Technology, University of Twente (Enschede, Twente University Press).

Guri-Rosenblit, S. (1998) Future agendas of distance-teaching and mass-oriented universities, in: A. Szucs \& A. Wagner (Eds) Universities in a digital age: transformation, innovation, and tradition: Proceedings of the Seventh EDEN (European Distance Education Network) Annual Conference (vol. 2) (Budapest, European Distance Education Network), 225-229.

Ling, P., Arger, G., Smallwood, H., Toomey, R., Kirkpatrick, D. \& Barnard, I. (2001) The effectiveness of models of flexible provision of higher education (Commonwealth of Australia). Available online at: http://www.dest.gov.au/archive/highered/eippubs/eip01_9/default.htm (accessed July 2003).

Middlehurst, R. (2003) Competition, collaboration and ICT: challenges and choices for higher education institutions, in: M. Van der Wende \& M. van der Ven (Eds) The use of ICT in higher education: a mirror of Europe (Utrecht, Lemma), 253-276.

Mioduser, D. \& Nachmias, R. (2001) WWW in education, in: H. Adelsberger, B. Collis \& J. Pawlowski (Eds) Handbook of information technology for education and training (Berlin, Springer Verlag), 23-43.

Morgan, G. (2003) Faculty use of course-management systems (Washington, ECAR). Available online at: http://www.educause.edu/ir/library/pdf/ecar_so/ers/ers0302/ (accessed July 2003).

Observatory of Borderless Education (2002) Web-based learning in Commonwealth universities. Available online at: www.obhe.ac.uk (accessed July 2003).

Oliver, R. \& Herrington, J. (2001) Teaching and learning online: a beginner's guide to e-learning and e-teaching in higher education (Mt Lawley, Western Australia, Edith Cowan University Centre for Research in Information Technology and Communications).

Van de Brande, L. (1993) Flexible and distance learning (Chichester, John Wiley). 
48 W. de Boer and B. Collis

Zimitat, G. (2002) Benchmarking flexible learning: a pilot study, in A. Goody \& D. Ingram (Eds) Proceedings of the 4th World Conference of the International Consortium for Educational Development (ICED) (Perth, Western Australia). Also available online at: http://www.csd.uwa.edu.au/ iced2002/publication/Craig_Zimitat.pdf (accessed July 2003). 